\title{
Avaliação farmacognóstica e microbiológica da droga vegetal camomila (Chamomilla recutita L.) comercializada como alimento em Cascavel - Paraná
}

\author{
LUCCA, P.S.R. ${ }^{1}$; ECKERT, R.G ${ }^{2}$; SMANHOTTO, V. ${ }^{1}$; KUHN, L.M. ${ }^{1}$; MINANTI, L.R. ${ }^{1}$ \\ ${ }^{1}$ Faculdade Assis Gurgacz - FAG. Av. das Torres, 500. CEP: 85806-095, Cascavel-Brasil "patricialucca@fag.edu.br \\ ${ }^{2}$ Universidade Estadual do Oeste do Paraná - UNIOESTE. Rua Universitária, 1619. CEP: 85819-011, Cascavel- \\ Brasil
}

RESUMO: As plantas medicinais, dentre elas a camomila, têm sido muito utilizadas na forma de droga vegetal pela população em geral, como importantes alternativas alimentícias e terapêuticas. Considerando que a fiscalização sanitária destes produtos é precária, este quadro torna-se preocupante, visto que, um produto em condições inadequadas para consumo pode acarretar vários riscos ao consumidor. Diante disso, este trabalho teve por objetivo realizar avaliação farmacognóstica e microbiológica em quinze amostras de chá de camomila comercializadas na cidade de Cascavel, Paraná. A metodologia adotada para a realização dos testes foi a preconizada pela Farmacopéia Brasileira (1988, 1996, 1998). O estudo de autenticidade revelou que todas as amostras eram constituídas por Chamomilla recutita L., porém na maioria das amostras os capítulos florais apresentavam-se excessivamente destruídos. Seis amostras apresentaram teor de materiais estranhos acima de 5\%. Quanto ao doseamento de óleo essencial, todas as amostras foram insatisfatórias, visto que, apresentaram apenas traços de óleos essenciais, ou seja, valores abaixo de $0,4 \%$, sendo este valor o mínimo exigido pela Farmacopéia. Com relação às análises de bolores e leveduras foi verificado que quatro amostras apresentaram valores acima do limite de $10^{4}$ UFC mL-1, conforme preconizado pela Organização Mundial de Saúde. A partir dos dados obtidos concluiu-se que a camomila comercializada na cidade de Cascavel - Paraná apresenta problemas com relação à qualidade, sendo necessário definir medidas adequadas de controle higiênico sanitário ao longo da cadeia de produção, para garantir a qualidade e segurança destes produtos.

Palavras-chave: camomila, qualidade, segurança alimentar

\begin{abstract}
Pharmacognostic and microbiological evaluation of the medicinal plant chamomile (Chamomilla recutita L.) commercialized as food in Cascavel Municipality, Paraná State, Brazil. Medicinal plants, including chamomile, have been largely used by the general population as important food and therapeutic alternatives. Considering that the sanitary control of such products is precarious, this situation becomes worrisome since a product presenting unsuitable conditions for consumption can lead to several risks to the consumer. Thus, the present study aimed to perform a pharmacognostic and microbiological evaluation of fifteen samples of chamomile tea commercialized in Cascavel Municipality, Paraná State, Brazil. The adopted methodology for the tests was that recommended by the Brazilian Pharmacopoeia $(1988,1996$, 1998). The authenticity study indicated that all samples were constituted of Chamomilla recutita L.; however, most samples had excessively destroyed flower capitula. Six samples had levels of strange materials above $5 \%$. As regards essential oil evaluation, all samples were unsatisfactory, since they only had essential oil traces, i.e. values under $0.4 \%$, which is the lowest value accepted by the Pharmacopoeia. As regards mold and yeast analyses, four samples had values above the limit of $10^{4} \mathrm{UFC} \mathrm{mL}-1$, according to that recommended by the World Health Organization. The obtained data suggest that the chamomile commercialized in Cascavel Municipality has problems regarding quality; thus, establishing suitable procedures for sanitary hygienic control in its production chain is needed to assure the quality and the safety of such products.
\end{abstract}

Key words: chamomile, quality, food safety

Recebido para publicação em 08/09/08

Aceito para publicação em 19/01/10

Rev. Bras. PI. Med., Botucatu, v.12, n.2, p.153-156, 2010. 


\section{INTRODUÇÃO}

Os produtos fitoterápicos vêm sendo utilizados como importantes alternativas terapêuticas em razão de diversos fatores, como o alto custo dos medicamentos sintéticos ou o próprio modismo, tornando seu consumo preocupante quando considerado que a fiscalização destes produtos é precária, representando vários riscos ao consumidor (Amaral et al., 2001).

A RDC 48/2004, estabelece normas para registro de medicamentos fitoterápicos no Brasil, e permite o registro como fitoterápico apenas do derivado de droga vegetal, que é o produto de extração da matéria prima vegetal: extrato, tintura, óleo, cera, exsudato, suco, etc. De acordo com a abrangência, "não é objeto de registro ou cadastro a planta medicinal ou suas partes, após processos de coleta, estabilização e secagem, podendo ser íntegra, rasurada, triturada ou pulverizada" (Brasil, 2004). Ou seja, drogas vegetais não são consideradas como medicamentos e sim chás (alimento).

Porém, estes chás, mesmo quando utilizados como me-dicamentos, geralmente são comercializados como alimento, dados a facilidade maior de regulamentação junto a Agência Nacional de Vigilância Sanitária (Gomes et al., 2007).

Estes produtos não devem trazer indicação terapêutica, e não são exigidos teores mínimos de constituintes químicos característicos de cada espécie vegetal, como é o caso da comercialização da planta como medicamento. É desejável e importante, no entanto, que tais produtos apresentem-se também dentro de padrões mínimos de qualidade (Brandão et al., 2002).

Dentre as espécies vegetais mais utilizadas na forma de chá está a camomila, uma das plantas de uso mais antigo pela medicina tradicional européia, sendo atualmente incluída em Farmacopéias de diversos países (Lorenzi \& Matos, 2002).

A Chamomilla recutita, tem como nomes populares no Brasil, camomila, maçanilha, camomilacomum, camomila-romana, camomila-dos-alemães, camomila verdadeira, camomila vulgar, matricária e camomila-legítima (Lorenzi \& Matos, 2002). Os capítulos florais possuem óleo essencial, responsável por diversos efeitos farmacológicos, como calmante, antiinflamatório, analgésico, antiespasmódico, carminativo, cicatrizante e emenagogo (Lorenzi \& Matos, 2002; Mapeli et al., 2005; Amaral et al., 2003).

No Brasil o estado do Paraná é líder na produção de camomila e foi responsável pela produção de 600 toneladas da droga na safra de 2007 (Oliveira, 2009).

Diante disso, este trabalho teve por objetivo realizar avaliação farmacognóstica e microbiológica em quinze amostras de chá de camomila comercializadas na cidade de Cascavel, Paraná.

\section{MATERIAL E MÉTODO}

\section{Obtenção e preparo das amostras}

Foram analisadas quinze amostras comerciais de camomila, procedentes de farmácias, ervanarias e supermercados. As amostras foram classificadas segundo suas procedências em três grupos: $(A)$ cinco amostras de chás adquiridas em farmácias $(1,2,3$, 4, 5); (B) cinco comercializadas a granel em ervanarias (6, 7, 8, 9,10); (C) cinco comercializadas em supermercados $(16,17,18,19,20)$.

Para o preparo das amostras utilizou-se o quarteamento. Neste a droga é distribuída sobre uma área quadrada, dividida em quatro partes iguais; com a mão a mesma é distribuída por toda a área de modo homogêneo, rejeitando as porções contidas em dois quadrados opostos em uma das diagonais do quadrado. Juntaram-se as duas porções restantes e repetiu-se o processo, até adquirir quantidade de amostra necessária para proceder a análise (Farmacopéia Brasileira, 1988).

Todas as amostras foram analisadas em triplicata. As análises foram realizadas no laboratório de controle de qualidade da indústria de medicamentos Pronabel e também nos laboratórios da Faculdade Assis Gurgacz - FAG.

\section{Estudo de identidade}

Cada amostra foi analisada macro e microscopicamente, buscando identificar características morfológicas descritas na literatura para a espécie. Observaram-se as estruturas características da camomila comparando-se com o descrito na Farmacopéia Brasileira (1996) e Oliveira et al., (2005). Realizaram-se também análises organolépticas para verificação da cor, sabor e odor das amostras.

\section{Material estranho}

Segundo a Farmacopéia Brasileira, as drogas vegetais apresentam, frequentemente, certas impurezas que podem representar órgãos da própria planta diferente da parte usada; fragmentos de outras plantas; materiais de outra origem, como areia ou terra e desde que esses elementos não caracterizem falsificação ou adulteração do material, são considerados como material estranho. Para determinação do material estranho, $50 \mathrm{~g}$ de cada amostra foram espalhadas em uma camada fina sobre superfície plana. Manualmente a olho nu, foram separados os materiais estranhos à droga.

Pesou-se o material separado e determinouse a porcentagem com base no peso da tomada de ensaio. O limite de material estranho é de $5 \%$ (Farmacopéia Brasileira, 1998).

Cinzas totais e perda por dessecação 
As cinzas totais e perda por dessecação foram determinadas a partir do método propostos pela Farmacopéia Brasileira (1998). O valor de referência para cinzas totais é de no máximo $14 \%$ e para perda por dessecação é de 8 a 14\%.

\section{Determinação do teor de óleos essenciais}

O teor de óleos essenciais em drogas vegetais é determinado pelo processo de destilação por arraste a vapor, com auxilio do equipamento Clevenger (Farmacopéia Brasileira, 1988).

\section{Análise microbiológica}

Para os ensaios microbiológicos (contagem de aeróbios totais, bolores e leveduras), adotou-se a metodologia prescrita na Farmacopéia Brasileira IV (1988). As placas para contagem de aeróbios totais continham Tripticaseína de Soja, e foram incubadas durante quatro dias com temperatura entre 30 e $35^{\circ} \mathrm{C}$. Para contagem de bolores e leveduras utilizou-se 0 meio Sabouraud solidificado. Estas placas foram incubadas a $20-25^{\circ} \mathrm{C}$ durante sete dias.

\section{RESULTADO E DISCUSSÃO}

A Tabela 1 apresenta os resultados obtidos por amostras analisadas. O estudo de autenticidade revelou que todas as amostras eram constituídas por Chamomila recutita L. A Farmacopéia Brasileira preconiza que a droga deve ser constituída de capítulos florais inteiros, e na maior parte das amostras estes (86,67\%) se encontravam bastante destruídos, o que pode ser indício de manuseio excessivo ou má conservação. Apenas as amostras 1 e 13 apresentavam os capítulos florais inteiros.

$\mathrm{Na}$ análise organoléptica verificou-se uma coloração escura, assim como o odor fraco em seis amostras (3, 4,10, 14 e 15). Este problema pode ter sido decorrente de um processo inadequado de secagem, em que foram utilizadas temperaturas excessivas durante o processo.

$\mathrm{Na}$ análise de material estranho, como se pode observar na Tabela 1, seis das quinze amostras ultrapassaram os $5 \%$ de tolerância especificados pela Farmacopéia Brasileira (1996) para material estranho. Além disso, foram detectados insetos vivos nas amostras $6,7 \mathrm{e}$ 8 e insetos mortos nas amostras 11 e 5 .

As particularidades como a presença de insetos, podem estar relacionados à colheita $e$ transporte pós-colheita inadequados, assim como, falta de controle de qualidade antes e após a embalagem da camomila, pois a amostra que continha insetos vivos apresentava problemas em relação ao lacre da embalagem, o que possibilitava a entrada dos mesmos.

A análise de perda por dessecação constatou que todas as amostras estavam adequadas quanto ao valor de referência estabelecido (14\%).

Com relação à determinação de cinzas totais os resultados obtidos indicam que todas as amostras analisadas apresentam-se com o teor de cinzas conforme estabelecido pela Farmacopéia Brasileira,

TABELA1. Resultados das análises farmacognósticas e microbiológicas realizadas nas amostras de camomila comercializadas na cidade de Cascavel/PR.

\begin{tabular}{cccccc}
\hline Amostra & $\begin{array}{c}\text { Material } \\
\text { estranho }\end{array}$ & $\begin{array}{c}\text { Perda por } \\
\text { dessecação }\end{array}$ & $\begin{array}{c}\text { Cinzas } \\
\text { totais }\end{array}$ & $\begin{array}{c}\text { Aeróbios } \\
\text { totais(UFC mL-1) }\end{array}$ & $\begin{array}{c}\text { Bolores e } \\
\text { leveduras(UFC mL-1) }\end{array}$ \\
\hline 1 & $4.10 \%$ & $11.67 \%$ & $7.73 \%$ & $3,00 \times 10^{3}$ & $2,77 \times 10^{3}$ \\
2 & $10.90 \%$ & $12.00 \%$ & $8.90 \%$ & $2,38 \times 10^{4}$ & $1,90 \times 10^{3}$ \\
3 & $2.77 \%$ & $9.73 \%$ & $9.18 \%$ & $8,05 \times 10^{4}$ & $3,18 \times 10^{4}$ \\
4 & $3.40 \%$ & $9.00 \%$ & $6.20 \%$ & $1,06 \times 10^{4}$ & $2,10 \times 10^{4}$ \\
\hline 5 & $5.19 \%$ & $10.40 \%$ & $8.45 \%$ & $4,12 \times 10^{4}$ & $1,37 \times 10^{3}$ \\
6 & $9.90 \%$ & $11.53 \%$ & $8.47 \%$ & $1,28 \times 10^{4}$ & $2,90 \times 10^{3}$ \\
7 & $3.92 \%$ & $9.27 \%$ & $7.17 \%$ & $1,02 \times 10^{4}$ & $1,18 \times 10^{4}$ \\
8 & $10.10 \%$ & $12.13 \%$ & $8.55 \%$ & $1,30 \times 10^{4}$ & $3,90 \times 10^{3}$ \\
9 & $3.88 \%$ & $8.99 \%$ & $6.69 \%$ & $1,22 \times 10^{4}$ & $1,33 \times 10^{3}$ \\
\hline 10 & $3.12 \%$ & $10.77 \%$ & $6.87 \%$ & $1,12 \times 10^{4}$ & $1,19 \times 10^{3}$ \\
11 & $3.13 \%$ & $10.57 \%$ & $8.83 \%$ & $3,40 \times 10^{3}$ & $2,43 \times 10^{3}$ \\
12 & $10.90 \%$ & $12.00 \%$ & $8.90 \%$ & $2,38 \times 10^{4}$ & $1,90 \times 10^{3}$ \\
13 & $5.09 \%$ & $9.10 \%$ & $7.85 \%$ & $3,82 \times 10^{4}$ & $2,07 \times 10^{3}$ \\
14 & $3.78 \%$ & $9.70 \%$ & $7.19 \%$ & $1,22 \times 10^{4}$ & $1,88 \times 10^{4}$ \\
15 & $3.02 \%$ & $11.27 \%$ & $7.77 \%$ & $1,62 \times 10^{4}$ & $1,29 \times 10^{3}$ \\
\hline
\end{tabular}

Rev. Bras. PI. Med., Botucatu, v.12, n.2, p.153-156, 2010. 
o que representa quantidade adequada de material inorgânico nas amostras analisadas, indicando que as mesmas não possuem excesso de terra e/ou areia.

Quanto ao doseamento de óleo essencial todas as amostras foram insatisfatórias, visto que, apresentaram apenas traços de óleos essenciais, ou seja, valores abaixo de $0,4 \%$, sendo este valor o mínimo exigido pela Farmacopéia. Sabe-se que os chás comercializados como alimento não tem a obrigatoriedade legal de apresentarem teores de óleos essenciais dentro dos preconizados pela Farmacopéia, porém sabe-se também que a maior parte da população que busca o uso do chá, pretende fazê-lo pelo sabor agradável e também pelos possíveis benefícios que podem ser alcançados com o uso, fatores estes dependentes da presença de óleos essenciais no chá. Os baixos teores de óleo essenciais encontrados nas amostras indicam inadequação nos processos de produção, secagem e armazenagem das drogas vegetais.

Com relação as análise de contaminação por aeróbios totais verificou-se que todas as amostras estão dentro do preconizado pela Organização Mundial de Saúde que estabelece um máximo de $10^{7}$ UFC $\mathrm{mL}^{-1}$ para plantas medicinais que passarão por processo de aquecimento em água.

Com relação às análises de bolores e leveduras verificou-se que quatro amostras apresentaram valores acima do limite de $10^{4} \mathrm{UFC} \mathrm{mL}^{-1}$, conforme preconizado pela Organização Mundial de Saúde. Este excesso de bolores e leveduras representa a precária condição sanitária destas amostras.

Em pesquisa realizada por Brandão et al. (1998) em que foram analisadas 27 amostras de camomila comercializadas na região de Minas Gerais, todas apresentaram-se em desacordo com pelo menos um critério estabelecido pela Farmacopéia Brasileira.

Posteriormente, em trabalho semelhante foi realizado em Belo Horizonte com amostras comerciais de chá de boldo, camomila, entre outras plantas, apontou que todas as amostras de camomila apresentavam elevada porcentagem de elementos estranhos ou baixas concentrações de óleos voláteis (Brandão et al., 2002).

A comercialização destes produtos sem qualidade é fato preocupante, principalmente se levarmos em consideração que os mesmos são amplamente utilizados pela população das grandes cidades inclusive como recurso terapêutico.

Assim, após análise dos dados obtidos, conclui-se que os chás de camomila, comercializados na cidade de Cascavel - Paraná, não se encontram dentro dos padrões estabelecidos pela bibliografia. Diante disso, faz-se necessário definir medidas adequadas de controle higiênico-sanitário para garantir a qualidade e segurança destes produtos.

\section{AGRADECIMENTO}

Agradecemos a Pronabel Laboratório Industrial e a Faculdade Assis Gurgacz - FAG pelo apoio durante a realização deste trabalho.

\section{REFERÊNCIA}

AMARAL, F.M.M. et al. Avaliação da qualidade de drogas vegetais comercializadas em São Luís/Maranhão. Revista Brasileira de Farmacognosia, v.13, p.27-30, 2003.

AMARAL, F.M.M. et al. Qualidade microbiológica da cascas do caule de Tabebuia avellanedae Lor. Ex Griseb. comercializadas em São Luis/Maranhão. Revista Visão Acadêmica, v.2, n.2, p.19-23, 2001.

BRANDÃO, M.G.L. et al. Vigilância de fitoterápicos em Minas Gerais. Verificação da qualidade de diferentes amostras comerciais de camomila. Cadernos de Saúde Pública, v.14, n.3, p.613-6, 1998.

BRANDÃO, M.G.L. et al. Qualidade de amostras comerciais de chás de plantas medicinais. Revista Brasileira de Plantas Medicinais, v.5, n.1, p.56-9, 2002. BRASIL. Ministério da Saúde. Agência Nacional de Vigilância Sanitária. Resolução RDC 48 de 16 de março de 2004. Dispões sobre o registro de medicamentos fitoterápicos. Diário Oficial da União, Brasília, DF, 18 mar. 2004.

FARMACOPÉIA Brasileira. 4. ed. São Paulo: Atheneu, 1988. p.V.4.2-4.2.5.

FARMACOPÉIA Brasileira. 4. ed. São Paulo: Atheneu, 1996. p.V.4.2-4.2.7.

FARMACOPÉIA Brasileira. 4. ed. São Paulo: Atheneu, 1998. p.V.4.2-4.2.2.

GOMES, E.C.; ELPO, E.R.S.; NEGRELLE, R.R.B. Armazenagem de chás no setor supermercadista. Ciência e Tecnologia de Alimentos, v.27, n.4, p.675-80, 2007.

LORENZI, H.; MATOS, F.J.A. Plantas medicinais do Brasil nativas e exóticas. São Paulo: Instituto Plantarum, 2002. p.147-8.

MAPELI, N.C. et al. Produção de biomassa e de óleo essencial dos capítulos florais da camomila em função de nitrogênio e fósforo. Horticultura Brasileira, v.23, n.1, p.42-6, 2005.

OLIVEIRA, O.; AKISUE, G.; AKISUE, K.M. Farmacognosia. São Paulo: Atheneu, 2005. p.19-28.

OLIVEIRA, R. Paraná mantém liderança da produção de camomila. Online. Disponível em: <http:// www.paranaonline.com.br/ editoria/economia/news/ 324611/>. Acesso em: 14 jan. 2009.

WORLD HEALTH ORGANIZATION. Quality control methods for medicinal plant materials. New York: WHO, 1992. 122p. 